\title{
Efeitos da imagética motora no membro superior parético após lesão medular traumática: relato de caso
}

\author{
Effects of motor imagetics in the paretic upper member \\ after traumatic medular injury: case study
}
Efectos de las imágenes motrices en el miembro parético alto después de uma lesión espinal traumática: estudio de caso

Mylena Gonçalves Fonseca ${ }^{1}$, Anne Karoline Barros Brasil' ${ }^{1}$, Larissa Mielly da Silva Gomes ${ }^{1}$, Carolina Kosour ${ }^{2}$, Adriana Teresa Silva Santos², Gabriela Xavier Santos ${ }^{3}$, Luciana Maria dos Reis²

1.Graduando do curso de Fisioterapia da Universidade Federal de Alfenas (UNIFAL-MG), Alfenas-MG, Brasil.

2.Fisioterapeuta, docente do curso de Fisioterapia da Universidade Federal de Alfenas (UNIFAL-MG), Alfenas-MG, Brasil.

3. Mestranda do Programa de Pós-Graduação em Ciências da Reabilitação da Universidade Federal de Alfenas (UNIFAL-MG), Alfenas-MG, Brasil.

\section{Resumo}

O trauma raquimedular (TRM) causa inúmeras limitações funcionais. A imagética motora (IM) é uma técnica utilizada para melhorar a função motora. Objetivo. Analisar efeitos da IM associado ao Protocolo Shapping na funcionalidade do membro superior (MMSS) parético após TRM. Método. Estudo de caso com indivíduo tetraparético após TRM incompleto, nível C5. Realizou-se 12 sessões de IM em MMSS e avaliação pela Motor Activity Log (MAL) e Fugl Meyer Assessment. Resultados. Observou-se ganho na funcionalidade MMSS na Escala Fugl Meyer e Motor Activity Log. Conclusão. Observou-se resultados satisfatórios da IM no desempenho motor de MMSS em indivíduo tetraparético após TRM.

Unitermos. Trauma Raquimedular; Paresia; Reabilitação; Imagem

\begin{abstract}
Spinal cord trauma (MRT) causes numerous functional limitations. Motor imagery (IM) is a technique used to improve motor function. Objective. To analyze the effects of MI associated with the Shapping Protocol on paretic upper limb functionality (MMSS) after TRM. Method. Case study with a tetraparetic individual after incomplete SCT, level C5. There were 12 IM sessions in MMSS and evaluation by Motor Activity Log (MAL) and Fugl Meyer Assessment. Results. There was a gain in the MMSS functionality in the Fugl Meyer Scale and Motor Activity Log. Conclusion. satisfactory results of MI were observed in the motor performance of MMSS in a tetraparetic individual after TRM.
\end{abstract}

Keywords. Spinal Trauma; Paresis; Rehabilitation; Image 


\section{Resumen}

El trauma de la médula espinal (MRT) causa numerosas limitaciones funcionales. Las imágenes motoras (IM) es una técnica que se utiliza para mejorar la función motora. Objetivo. Analizar los efectos del IM asociado con el Shapping Protocol sobre la funcionalidad parética del miembro superior (MMSS) después de TRM. Método. Estudio de caso con un individuo tetraparético tras TCS incompleto, nivel C5. Hubo 12 sesiones de mensajería instantánea en MMSS y evaluación por el registro de actividad motora (MAL) y la evaluación Fugl Meyer. Resultados. Hubo una ganancia en la funcionalidad del MMSS en la Escala de Fugl Meyer y en el Registro de Actividad Motora Conclusión. se observaron resultados satisfactorios del IM en el desempeño motor del MMSS en un individuo tetraparético después de TRM.

Palabras clave: trauma espinal; paresia; rehabilitación; imagen

Trabalho realizado na Universidade Federal de Alfenas (UNIFAL-MG), Alfenas-MG, Brasil.

Conflito de interesse: não

Recebido em: 09/11/2020

Aceito em: 17/02/2021

Endereço para correspondência: Luciana M Reis. Av. Jovino Fernandes de Sales 2600. Santa Clara, Alfenas-MG, Brasil. CEP 37133-840. Email: reislucianamaria@gmail.com

\section{INTRODUÇÃO}

O Trauma Raquimedular (TRM) é uma anormalidade funcional que abrange todo o tipo de injúria nas estruturas que compõem o canal medular e leva a disfunções como alteração sensitiva, motora, autonômica e psicoafetiva, dependente do local onde ocorreu o dano ${ }^{1}$.

As alterações funcionais no TRM se apresentam na forma de plegia ou paresia, caracterizadas por perda total ou parcial dos movimentos, respectivamente. Além disso, ocorrem alterações sensitivas e de tônus muscular, com modificação dos reflexos profundos e superficiais. Disfunções secundárias como dor neuropática, ossificação heterotópica, osteoporose, trombose venosa profunda (TVP), entre outras podem ser observadas ${ }^{1,2}$.

Os TRMs possuem origem traumática ou não traumática. A traumática representa $80 \%$ dos casos, ocasionada por traumas na coluna, quedas e acidentes 
automobilísticos. Enquanto as lesões não traumáticas correspondem a $20 \%$ dos casos $^{2}$.

A incidência mundial de TRM é de 15 a 40/milhão de habitantes por ano. No Brasil a incidência real é desconhecida, visto que esta condição não ocorre notificação, porém pesquisas indicam que haja aproximadamente 40/ano a cada milhão de habitantes. A maior prevalência no Brasil está na população jovem, com predomínio nos homens e a taxa de morbimortalidade tende a subir 4\% ao ano. Ademais, o TRM demanda alto impacto socioeconômico ao país. É importante que o acompanhamento multiprofissional se inicie na fase aguda ${ }^{3}$.

Após a lesão, estes pacientes perdem funcionalidade dos membros, com maior comprometimento das mãos nos membros superiores (MMSS). Assim, a reabilitação de MMSS se faz importante, com treinamento intensivo das mãos, para adquirir funcionalidade na realização das Atividades de Vida Diária (AVD's) ${ }^{4}$.

A Imagética Motora (IM) é um recuso atualmente estudado no tratamento das sequelas neurológicas. É definida como um processo dinâmico, no qual o sujeito evoca o plano motor para uma ação e imagina sua execução. Na IM, as ações simuladas são de fatos reais, pois mesmo não executadas, apresentam similaridades psicofísicas e fisiológicas com os movimentos corporais executados ${ }^{4,5}$.

Os benefícios da IM estão voltados para a modulação plástica de circuitos neurais, desenvolvendo aprendizado 
motor durante a reabilitação, consequentemente, aumento da capacidade de concentração e conscientização na execução da tarefa. Forma de terapia recente, que vem apresentando resultados satisfatórios em disfunções neurológicas7. A IM no tratamento de MMSS no TRM pode ocasionar modulação cortical, ocasionando ativação das áreas pré-motora, sensório-motora e motora primária ${ }^{5}$.

Atualmente, existem poucos estudos abordando a IM na reabilitação pós TRM. Os estudos estabelecem protocolos de IM associada a fisioterapia convencional, porém não foram encontrados estudos com o Protocolo Shaping com a IM em TRM.

O objetivo do presente estudo foi avaliar os efeitos da IM, com o protocolo Shaping, nas funções motora e sensorial de MMSS na tetraparesia decorrente de TRM.

\section{MÉTODO}

O estudo foi realizado na Clínica Escola de Fisioterapia da Universidade Federal de Alfenas (UNIFAL-MG), com um paciente selecionado por conveniência, sexo masculino, 30 anos, quadro de tetraparesia decorrente de TRM incompleto, a nível da quinta vértebra cervical (C5), segundo Escala ASIA. Indivíduo apresenta-se cadeirante com movimentação limitada de MMSS. Realizou tratamento fisioterapêutico no ambiente hospitalar logo após a lesão e retornou ao tratamento dois anos após alta hospitalar.

O estudo foi aprovado pelo Comitê de Ética em Pesquisa da Universidade Federal de Alfenas (UNIFAL-MG) 
(CAAE 81112117.0.0000.5142) e seguiu a Resolução 466/12 do Conselho Nacional de Saúde.

\section{Procedimento}

A forma de avaliação se deu através de duas escalas frequentemente utilizadas em estudos, a Motor Activity Log $(\mathrm{MAL})^{6}$ e Fugl Meyer Assessment ${ }^{7}$, consideradas de fácil aplicabilidade e confiabilidade, sendo validada no Brasil, para mensuração do comprometimento motor/sensorial de MMSS, realizadas antes e após a intervenção.

O protocolo de IM foi realizado em doze sessões com duração de 60 minutos cada, duas vezes por semana, em um período de três meses. O paciente instruído a realizar, com ambos os membros, atividades selecionadas do Protocolo Shaping, voltado para AVD's, realizado com materiais como talheres, recipientes de diferentes tamanhos, feijões, cones, bolas de gude, massa de modelar, bola terapêutica e dominós, totalizando 10 tarefas.

O sujeito assistiu a vídeos gravados pelos examinadores através da câmera de Smartphone da marca Samsung em um notebook da marca Lenovo. 0 procedimento seguiu as seguintes etapas: $1^{0}$ : assistiu atenciosamente aos vídeos, que exibiram a atividade que posteriormente seria praticada em 1 série de 10 repetições; 20: foi instruído a fechar os olhos e realizar mentalmente a tarefa assistida por 10 vezes; e na $3^{\circ}$ : executou por 10 
vezes a atividade assistida e imaginada, associada ao comando verbal do pesquisador.

\section{RESULTADOS}

Os resultados foram tabulados com valores brutos obtidos pré e pós intervenção nas escalas (MAL) e Fugl Meyer Assessment, para os MMSS. Posteriormente, realizado cálculo de porcentagem nas mesmas condições.

A MAL é composta por 30 itens. Na avaliação inicial do membro superior direito (MSD), o sujeito relatou não conseguir realizar 12 itens.

Na avaliação final observou-se ganhos em 3 itens não realizados anteriormente e ganho significativo em 6 itens avaliados no MSD. Os demais itens avaliados se mantiveram semelhantes ao inicial (Tabela 1).

Tabela 1. Valores obtidos pré e pós intervenção MSD, utilizando a Escala Motor Activity Log.

\begin{tabular}{lccc}
\hline Escala Motor Activity Log & $\begin{array}{c}\text { Avaliação } \\
\text { Pré }\end{array}$ & $\begin{array}{c}\text { Avaliação } \\
\text { Pós }\end{array}$ & $\begin{array}{c}\text { Pontuação } \\
\text { Máxima }\end{array}$ \\
\hline Escores & 67 & 90 & 150 \\
\hline Porcentagem Geral & 44,6 & 60 & 100 \\
\hline Porcentagem de ganho & & 15,4 & \\
\hline
\end{tabular}

MSD = membro superior direito.

No membro superior esquerdo (MSE), na avaliação pré intervenção, o paciente não conseguia realizar 12 tarefas. Já na avaliação final, observou-se ganho em 3 itens não 
realizados anteriormente, melhora em 4 itens e redução em 4 itens. Os demais itens avaliados mantiveram-se iguais (Tabela 2). Os valores em porcentagem mostraram ganho de $15,4 \%$ no MSD e 8,7 \% no MSE, comparando as avaliações (Tabela 1 e 2).

Tabela 2. Valores obtidos pré e após intervenção MSE, utilizando a Escala Motor Activity Log.

\begin{tabular}{lccc}
\hline Escala Motor Activity Log & $\begin{array}{c}\text { Avaliação } \\
\text { Pré }\end{array}$ & $\begin{array}{c}\text { Avaliação } \\
\text { Pós }\end{array}$ & $\begin{array}{c}\text { Pontuação } \\
\text { Máxima }\end{array}$ \\
\hline Escores & 67 & 80 & 150 \\
\hline Porcentagem geral & 44,6 & 53,3 & 100 \\
\hline Porcentagem de ganho & & 8,7 & \\
\hline
\end{tabular}

$\mathrm{MSE}=$ Membro Superior esquerdo.

Em relação a Escala Fugl Meyer, na avaliação inicial, obteve-se escore de 39 de 66 pontos disponíveis, relacionados a função motora de MSD e um escore total de 75 dos 126 disponíveis. Após intervenção, observou-se aumento, alcançando escore de 46 na função motora e escore total de 88 (Tabela 3). Para o MSE, na avaliação inicial, obteve-se um escore de 39 na função motora e 74 de escore total. Na avaliação pós intervenção, observou aumento, alcançando escore de 46 na função motora e escore total de 84 (Tabela 4). Houve aumento de 7,3 \% na função de MSD e 7,9 \% no MSE (Tabela 3 e 4). 
Tabela 3. Valores obtidos pré e pós intervenção MSD, utilizando a Escala Fugl Meyer de Membro Superior.

\begin{tabular}{lccc}
\hline & $\begin{array}{c}\text { Avaliação } \\
\text { Pré }\end{array}$ & $\begin{array}{c}\text { Avaliação } \\
\text { Pós }\end{array}$ & $\begin{array}{c}\text { Pontuação } \\
\text { Máxima }\end{array}$ \\
\hline A. Extremidade Superior & 28 & 34 & 36 \\
\hline B. Punho & 7 & 4 & 14 \\
\hline C. Mão & 1 & 3 & 6 \\
\hline D. Coordenação/ Velocidade & 3 & 46 & 12 \\
\hline Total A - D (função motora) & 39 & 12 & 24 \\
\hline H. Sensibilidade & 8 & 15 & 24 \\
\hline I. Movimento Articular Passivo & 14 & 15 & 126 \\
\hline J. Dor Articular & 14 & 88 & 100 \\
\hline ESCORES & 75 & 69,8 & \\
\hline Porcentagem geral & 62,5 & 7,3 & 16 \\
\hline Porcentagem de ganho & & & \\
\hline
\end{tabular}

MSD $=$ Membro Superior direito.

\section{DISCUSSÃO}

No presente estudo foram observados ganho no comportamento motor/sensorial de MMSS por meio da Escala Fugl Meyer, com porcentagem de ganho de 7,3\% no MSD e de $7,9 \%$ no MSE.

Em relação a Escala Motor Activity Log observou-se ganho na função motora de cerca de $15 \%$ em MSD e 8,7\% no MSE.

Observou-se queda no rendimento em quatro itens avaliados na Escala Motor Activity Log. Esta queda pode ser explicada devido ao paciente relatar a presença de dor no MSE no momento da avaliação. 
Tabela 4. Valores obtidos pré e pós intervenção MSE, utilizando a Escala Fugl Meyer de Membro Superior.

\begin{tabular}{|c|c|c|c|}
\hline & Avaliação Pré & $\begin{array}{c}\text { Avaliação } \\
\text { Pós }\end{array}$ & $\begin{array}{l}\text { Pontuação } \\
\text { Máxima }\end{array}$ \\
\hline A. Extremidade Superior & 28 & 34 & 36 \\
\hline B. Punho & 7 & 5 & 10 \\
\hline C. Mão & 1 & 4 & 14 \\
\hline D. Coordenação/ Velocidade & 3 & 3 & 6 \\
\hline Total A - D (função motora) & 39 & 46 & 66 \\
\hline H. Sensibilidade & 8 & 12 & 12 \\
\hline I. Movimento Articular Passivo & 13 & 13 & 24 \\
\hline J. Dor Articular & 13 & 13 & 24 \\
\hline ESCORES & 74 & 84 & 126 \\
\hline Porcentagem geral & 58,7 & 66,6 & 100 \\
\hline Porcentagem de ganho & & 7,3 & \\
\hline
\end{tabular}

$\mathrm{MSE}=$ Membro Superior esquerdo.

Um estudo mostra que a prática da IM com atividades para MMSS de pacientes após TRM associado a fisioterapia convencional é uma ferramenta importante para a neuroplasticidade cortical. Os participantes foram avaliados por meio de magnetoencefalografia (MEG) e observou-se que a IM associado a fisioterapia convencional foi responsável pela neuroplasticidade nos participantes com $\mathrm{TRM}^{4}$. 
Um estudo de caso com lesão completa pós TRM a nível T10 foi realizado para a verificação da eficácia da utilização de IM voltada para o treino de marcha e manutenção da postura ortostática. Foi realizado apenas uma sessão de intervenção onde foram trabalhados quatro comandos diferentes de IM em ortostatismo. Ao final do estudo, por meio de avaliação eletromiográfica (EMG), observou-se aumento da intensidade do sinal de para os músculos: reto femoral, bíceps femoral e tibial anterior bilateralmente, durante a IM, comparada ao momento de repouso. Este estudo sugere que a IM leva a uma modulação cortical a partir da imaginação do movimento da marcha em lesão medular completå ${ }^{8}$.

Sabe- se que em TRMs incompletos, existe algum grau de continuidade axonal na área que foi lesada. Desta forma, a imaginação do movimento leva à ativação cortical, que estimula a excitabilidade das vias corticoespinhais. A ativação do córtex motor durante a IM, leva o paciente a tentativa de realização do movimento propriamente dito de forma mais fidedigna, diferentemente de casos em que não se tenha utilizado a imaginação do movimento previamente a sua tentativa de realização ${ }^{5}$.

O protocolo Shaping utilizado no estudo incentiva o paciente na realização de atividades que se assemelham as AVD's, com objetivo de melhora do MMSS parético. A utilização deste protocolo traz inúmeros benefícios, dentre eles, a melhora da qualidade e quantidade de movimento 
do membro parético, promovendo recuperação da funcionalidade e consequentemente a qualidade de vida ${ }^{9}$.

O presente estudo reforça os resultados apresentados nestas pesquisas, a qual mostra que a utilização da IM na reabilitação de pacientes com TRM se mostra como uma nova possibilidade de terapia para melhora da funcionalidade do membro. A utilização da IM na reabilitação destes pacientes, sugere que ocorra uma modulação cortical na imaginação do movimento, de forma a proporcionar melhor desempenho motor/sensorial.

A partir do presente estudo, se faz necessário a realização de novos estudos com amostra maior, permitindo melhor análise dos efeitos da IM, no intuito de fornecer nova ferramenta para a prática clínica na reabilitação de indivíduos pós TRM.

\section{CONCLUSÃO}

A intervenção fisioterapêutica, por meio da imagética motora, promoveu resultados satisfatórios na funcionalidade de membros superiores em um sujeito com tetraparesia após lesão medular traumática incompleta. Porém, é necessário a realização de novos estudos randomizados e duplo-cego objetivando melhor análise dos efeitos da IM, visto que o atual estudo é composto de amostra única. 


\section{REFERÊNCIAS}

1.Schoeller SD, Grumann ARS, Martini AC, Forner S, Sader LT, Nogueira GC. Knowing to care: characterization of individuals with spinal cord injury treated at a rehabilitation center. Fisioter Mov 2015;28:77-83. http://dx.doi.org/10.1590/0103-5150.028.001.ao08 2.Capelari TV, Borin JS, Grigol M, Saccani R, Zardo F, Cechetti F. Evaluation of muscle strength in medullar injury: a literature review. Coluna 2017;16:323-9. http://dx.doi.org/10.1590/s1808185120171604179802

3.Jong LD, Van Wijck F, Stewart RE, Geurts ACH, Dijkstra PU. Content of conventional therapy for the severely affected arm during subacute rehabilitation after stroke: an analysis of physiotherapy and occupational therapy practice. Physiother Res Inter 2017;23:1683. http://dx.doi.org/10.1002/pri.1683

4.Rienzo F, Guillot A, Mateo S, Daligault S, Delpuech C, Rode G, et al. Neuroplasticity of prehensile neural networks after quadriplegia. Neuroscience 2014;274:82-92.

http://dx.doi.org/10.1016/j.neuroscience.2014.05.021

5. Alves SS, Ocamoto GN, Camargo OS, Santos ATS, Terra AMSV. Effects of virtual reality and motor imagery techniques using Fugl Meyer Assessment scale in post-stroke patients. Inter J Ther Rehab 2018;25:587-96. http://dx.doi.org/10.12968/ijtr.2018.25.11.587

6.Chuang I-C, Lin K-C. Using Rasch Analysis to Validate the Motor Activity Log and the Lower Functioning Motor Activity Log in Patients With Stroke. Phys Ther 2017;99:1030-40.

https://doi.org/10.1093/ptj/pzx071

7. Michaelsen SM, Rocha AS, Knabben RJ, Rodrigues LP, Fernandes CGC. Tradução, adaptação e confiabilidade interexaminadores do manual de administração da escala de Fugl-Meyer. Rev Bras Fisioter $2011 ; 15: 80-8$.

http://dx.doi.org/10.1590/s1413-

35552011000100013

8.Lacerda MO. Modulação da atividade eletromiográfica durante diferentes comandos de imagética da marcha em paciente com lesão medular completa: estudo de caso (monografia). Natal: Universidade Federal do Rio Grande do Norte, 2017, 31p. http://monografias.ufrn.br/handle/123456789/5462

9.Tonos D, Queiroz LF. Aplicação da Terapia de Contensão Induzida com protocolo adaptado para atendimento domiciliar e suas contribuições no quadro motor e na reabilitação de paciente pósacidente vascular encefálico. Cad Ter Ocupac UFSCAR 2015;23:54352. http://dx.doi.org/10.4322/0104-4931.ctoao0562 